\title{
Effect of Long Term Use of Carbamazepine on Lipid Profile in Adult Epileptic Patients
}

\author{
MD KHAIRUL KABIR PATWARY ${ }^{1}$, SHAKILA SULTANA ${ }^{2}$, MD SALAHUDDIN ${ }^{3}$, \\ ABU JAFOR MD SALAHUDDIN ${ }^{4}$, MOHAMMED SAYEED HASSAN ${ }^{4}$, MD KABIRUZZAMAN $^{5}$, \\ MD ABDUL ALIM ${ }^{5}$, RASHED IMAM ZAHID ${ }^{5}$, NURUDDIN MD EUSUF ${ }^{6}$, SUBASH KANTI DEY $^{7}$, \\ AHSAN HABIB ${ }^{7}$, BAHADUR ALI MIAH ${ }^{8}$, KANUJ KUMAR BARMAN ${ }^{8}$, MD RAFIQUL ISLAM $^{9}$.
}

\begin{abstract}
:
Objective: To evaluate the effect of long term use of carbamazepine on lipid profile in adult epileptic patients

Methodology: The study was conducted in the Department of Neurology at BSMMU, Dhaka over a period of 2 years from January 2010 to December 2011. Adult epileptic patients taking carbamazepine as anticonvulsant and attending the Epilepsy Clinic and Neurology OPD of BSMMU, Dhaka were the study population. A total of 107 cases and 107 controls were included in the study. Data were collected by interview of the patients, clinical examination and laboratory investigations using the research instrument

Result: The mean age of case and control groups were almost identical (23.3 $\pm 6.8 \mathrm{vs.}$ $23.8 \pm 6.4$ years, $p=0.972$ ). The proportion of male and female patients was similar in both the study groups. Of the 107 cases, more than $70 \%$ had generalized epilepsy and the rest (29\%) focal epilepsy. Of the 107 cases, $8 \%$ had family history of epilepsy. The prevalence of raised triglycerides and raised $L D L$ were observed to be significantly higher in the case group than those in the control group (35.5\% vs. $23.4 \%, p=0.049$ and $15 \%$ vs. $0.9 \%, p<0.001$ respectively). The prevalence of low HDL was also significantly higher in the former group than that in the latter group (43.9\% vs. $18.7 \%$, $p<0.001)$. The mean serum triglyceride and LDL were higher and mean HDL was lower in the case group than those in the control group. Over half $(51.4 \%)$ of the case group exhibited dyslipidemia compared to the control group (27.1\%). The risk of developing dyslipidemia in epileptic patients receiving carbamazepine for longer duration was nearly three-fold $(95 \%$ of $\mathrm{Cl}=1.6-5.0)$ higher than that in the control group $(p<0.001)$. There

is positive correlation between duration of carbamazepine treatment and lipid profile. Serum total cholesterol and triglycerides bear linear relationship with duration of treatment with carbamazepine $(r=0.201, p=0.038$ and $r=0.223, p=0.021$ respectively). The association of dyslipidemia with sex in epileptic patients receiving carbamazepine for more than 2 years. The proportion of dyslipdemia was considerably higher in the female patients than their male counterparts, although the difference was not statistically significant $(55.3 \%$ vs. $41.9 \%, p<0.211)$.

Conclusion: A conclusion can be made from the above mentioned result that long-term use of carbamazepine in epileptic patients may cause dyslipidemia and the risk of having dyslipidemia in such patients is 3 times greater than the normal healthy population.
\end{abstract}

Key words: Carbamazepine, lipid profile and Epilepsy.

1. Assistant Professor, National Institute of Neurosciences \& Hospital (NINS), Dhaka.

2. Resident, Department of Paediatrics, Bangabondhu Sheikh Mujib Medical University (BSMMU), Dhaka.

3. Registrar, Department of Medicine, Chittagong Medical College, Chittagong.

4. Junior Consultant, National Institute of Neurosciences \& Hospital (NINS), Dhaka.

5. Medical Officer, National Institute of Neurosciences \& Hospital (NINS), Dhaka.

6. Upazilla Health \&Family Planning Officer, Morelgonj, Bagerhat.

7. Assistant Professor, Department of Neurology, Bangabondhu Sheikh Mujib Medical University, Dhaka.

8. Associate Professor, Department of Neurology, Bangabondhu Sheikh Mujib Medical University, Dhaka.

9. Professor, Department of Neurology, Bangabondhu Sheikh Mujib Medical University (BSMMU), Dhaka. 


\section{Introduction:}

Epilepsy is a common chronic neurological disorder characterized by recurrent unprovoked seizures ${ }^{1,2}$. These seizures are transient signs and/or symptoms of abnormal, excessive or synchronous neuronal activity in the brain ${ }^{2}$. About 50 million people worldwide have epilepsy, with almost $90 \%$ of these people being in developing countries ${ }^{3}$. Epilepsy is more likely to occur in young children or people over the age of 65 years; however, it can occur at any time ${ }^{4}$.

Epilepsy is usually controlled, but cannot be cured with medication. However, over $30 \%$ of people with epilepsy do not have seizure control even with the best available medications ${ }^{5,6}$. The mainstay of treatment of epilepsy is anticonvulsant medications. Often, anticonvulsant medication may continue for life-long and can have major effects on quality of life. The choice among anticonvulsants and their effectiveness differs by epilepsy syndrome. Mechanisms, effectiveness for particular epilepsy syndromes, and side effects differ among the individual anticonvulsant medications.

Currently there are 20 medications approved by the Food and Drug Administration for the treatment of epileptic seizures: carbamazepine, clorazepate, clonazepam, ethosuximide, felbamate, fosphenytoin, gabapentin, lacosamide, lamotrigine, levetiracetam, oxcarbazepine, phenobarbital, phenytoin, pregabalin, primidone, tiagabine, topiramate, valproate semisodium, valproic acid, and zonisamide. Most of these drugs are available in Bangladesh but carbamazepine, valproic acid, lamotrigine, clonazepam, phenobarbital, phenytoin are commonly used.

Although there is scarcity of data regarding the sideeffects of anticonvulsants on Bangladeshi population, $88 \%$ of patients with epilepsy, in a European survey reported at least one anticonvulsant related side effect ${ }^{8}$. Most side effects are mild and "dose-related" and can often be avoided or minimized by the use of the smallest effective dose. Some examples include mood changes, sleepiness, or unsteadiness in gait. When anticonvulsant drugs are used in large quantities during long-term antiepileptic therapy, it may be associated with various metabolic abnormalities in connective tissues, endocrine system and the liver ${ }^{9}$. Anticonvulsants may alter liver function and increase the activity of hepatic microsomal enzyme system. This enzyme induction phenomenon is associated with an altered metabolism of various substances such as drugs and lipids ${ }^{9,10}$. This anomaly has focused attention on changes in lipid profile during long-term anticonvulsant therapy especially by alter liver function and increase the activity of the hepatic microsomal enzyme system ${ }^{10,11}$.

The effect of anti-epileptic drugs (AEDs) on serum lipid profile is controversial. Eiris and associates $(2000)^{12}$ found that the effects of long-term AED therapy on lipid profile and, particularly, on apolipoprotein serum levels increase risk of atherosclerosis-related disease. On the other hand, Tegkul and associates (2006) $)^{13}$ opposed such association. They suggested that 2 years AED monotherapy with VPA, CBZ or PB did not cause a significant level of concern for an atherogenic effect in children with epilepsy.

Carbamazepine elevates total cholesterol levels by 0 to $15 \%$ and HDL-cholesterol levels by 0 to $30 \%$. These effects are dosage independent and seem to be more pronounced in women ${ }^{14}$. However, one study ${ }^{15}$ showed levels of HDL-cholesterol decreased by almost $40 \%$. Although the effects of phenobarbital and phenytoin on serum lipid levels have been studied less frequently, reports ${ }^{14}$ indicate that they both elevate total cholesterol levels by 5 to $15 \%$. However, reported changes in HDL-cholesterol levels vary from a $40 \%$ decrease to a $45 \%$ increase. Triglyceride levels are not affected by any of the anticonvulsants ${ }^{15,16}$. They found that, carbamazepine treatment alters the serum lipid profile of the children in such a way that it facilitates the development of atherosclerosis ${ }^{16}$.

The influences of Carbamazepine on lipid profile of epileptic patients in Bangladesh have not been investigated. Therefore, a case-control study to investigate the effect of this drug on serum levels of lipids (triglyceride, total cholesterol, HDL and LDL) deemed essential.

\section{Methodology:}

Study design:A case control study was considered suitable for the study. 
Place and period of Study:The study was conducted in the Department of Neurology at BSMMU, Dhaka over a period of 2 years from January 2010 to December 2011.

\section{Study population:}

Adult epileptic patients taking carbamazepine as anticonvulsant and attending the Epilepsy Clinic and Neurology OPD of BSMMU, Dhaka were the study population.

Sample size:A total of 107 cases and 107 controls were included in the study.

Sampling procedure:The required number of cases and controls were selected consecutively.

\section{Inclusion criteria of cases:}

- Epileptic patients from 18 years onwards

- Patients who were taking carbamazepine for at least 2 years

\section{Exclusion criteria for cases:}

- Epileptic patients taking more than one anticonvulsant drugs

- Patients with diabetes mellitus, nephrotic syndrome, myxoedema which might affect the blood lipid.

- Any other chronic clinical conditions which can alter lipid profile.

- Patients taking carbamazepine for less than two years.

- Patients taking lipid lowering drugs.

Data processing and statistical analysis:Data were processed and analyzed using software SPSS (Statistical Package for Social Sciences) version 11.5. The test statistics used to analyze the data were descriptive statistics, Chi-square $\left(\mathrm{c}^{2}\right)$ test and Student's t Test. For all analytical tests, the level of significance was set at 0.05 and $p<0.05$ was considered significant.

\section{Results:}

A total of 214 adult participants were included in the study. Of them 107 were epileptic patients and considered as cases and another 107 apparently healthy subjects or non- epileptic patients were taken as controls. The mean age of case and control groups( Table-I) were almost identical $(23.3 \pm 6.8$ vs. $23.8 \pm 6.4$ years, $p=0.972$ ). The proportion of male and female patients was similar in both the study groups. Of the 107 cases, more than $70 \%$ had generalized epilepsy and the rest $(29 \%)$ focal epilepsy. Of the 107 cases, $8 \%$ had positive family history of epilepsy.

The prevalence of raised triglycerides and raised LDL were observed to be significantly higher in the case group than those in the control group (35.5\% vs. $23.4 \%, p=0.049$ and $15 \%$ vs. $0.9 \%, p<0.001$ respectively)( Fif-3). The prevalence of low HDL was also significantly higher in the former group than that in the latter group $(43.9 \%$ vs. $18.7 \%, p<0.001)$ (Fif-4). The mean serum triglyceride and LDL were higher and mean HDL was lower in the case group than those in the control group (Table II).

Over half $(51.4 \%)$ of the case group exhibited dyslipidemia compared to the control group $(27.1 \%)$ (Table-III). The risk of developing dyslipidemia in epileptic patients receiving carbamazepine for longer duration was nearly threefold $(95 \%$ of $\mathrm{Cl}=1.6-5.0)$ higher than that in the control group $(p<0.001)$ (Fig-1).

Table-I

Comparison of age between two groups

\begin{tabular}{|c|c|c|c|}
\hline \multirow[t]{2}{*}{$\overline{\text { Age (years) }}$} & \multicolumn{2}{|c|}{ Group } & \multirow[t]{2}{*}{$\mathrm{p}$-value } \\
\hline & Case $\quad(n=107)$ & Control $(n=107)$ & \\
\hline $18-25$ & $77(72.0)$ & $69(64.5)$ & \\
\hline $25-30$ & $15(14.0)$ & $25(23.4)$ & \\
\hline e" 30 & $15(14.0)$ & $13(12.1)$ & \\
\hline Mean \pm SD & $23.3 \pm 6.8$ & $23.8 \pm 6.4$ & 0.972 \\
\hline
\end{tabular}

* Figures in the parenthesis denote corresponding \%; 
Table-II

Comparison of lipid profiles between two groups

\begin{tabular}{lccc}
\hline Lipid profile $^{\#}$ & \multicolumn{2}{c}{ Group } & p-value \\
\cline { 2 - 3 } & $\begin{array}{c}\text { Case } \\
(\mathrm{n}=107)\end{array}$ & $\begin{array}{c}\text { Control } \\
(\mathrm{n}=107)\end{array}$ & \\
\hline Total cholesterol & $85(79.4)$ & $93(86.9)$ & \\
Normal $(<200 \mathrm{mg} / \mathrm{dl})$ & $22(20.6)$ & $14(13.1)$ & 0.144 \\
Raised $(>200 \mathrm{mg} / \mathrm{dl})$ Mean \pm SD & $175.3 \pm 30.6$ & $174.4 \pm 32.4$ & \\
Triglyceride & $69(64.5)$ & $82(76.6)$ & \\
Normal $(<150 \mathrm{mg} / \mathrm{dl})$ & $38(35.5)$ & $25(23.4)$ & 0.049 \\
Raised $(>150 \mathrm{mg} / \mathrm{dl})$ & $157.4 \pm 63.2$ & $133.1 \pm 68.1$ & \\
Mean \pm SD & & & \\
LDL & $91(85.0)$ & $106(99.1)$ & \\
Normal $(<130 \mathrm{mg} / \mathrm{dl})$ & $16(15.0)$ & $1(0.9)$ & \\
Raised $(>130 \mathrm{mg} / \mathrm{dl})$ & $112.4 \pm 23.2$ & $96.9 \pm 16.9$ & \\
Mean \pm SD & & & \\
HDL & $47(43.9)$ & $20(18.7)$ & \\
Low $(<40 \mathrm{mg} / \mathrm{dl})$ & $60(56.1)$ & $87(81.3)$ & \\
Normal $(\mathrm{e} " 40 \mathrm{mg} / \mathrm{dl})$ & $39.6 \pm 8.9$ & $43.3 \pm 10.6$ & \\
Mean \pm SD & & & \\
\hline
\end{tabular}

Figures in the parentheses indicate corresponding percentage;

\# Data were analysed using Chi-square $\left(\div^{2}\right)$ Test.

Table-III

Association between carbamazepine use in epileptic patients and dyslipidemia

\begin{tabular}{lccccc}
\hline Dyslipidemia & \multicolumn{2}{c}{ Group } & & Odds Ratio & p-value \\
\cline { 2 - 3 } & Case $(\mathrm{n}=107)$ & Control $(\mathrm{n}=107)$ & & $(95 \%$ Cl of OR $)$ & \\
\hline Present & $55(51.4)$ & $29(27.1)$ & & $2.8(1.6-5.0)$ & $<0.001$ \\
Absent & $52(48.6)$ & $78(72.9)$ & & \\
\hline
\end{tabular}

Figures in the parentheses indicate corresponding percentage;

\# Data were analysed using Chi-square $\left(\div^{2}\right)$ Test.

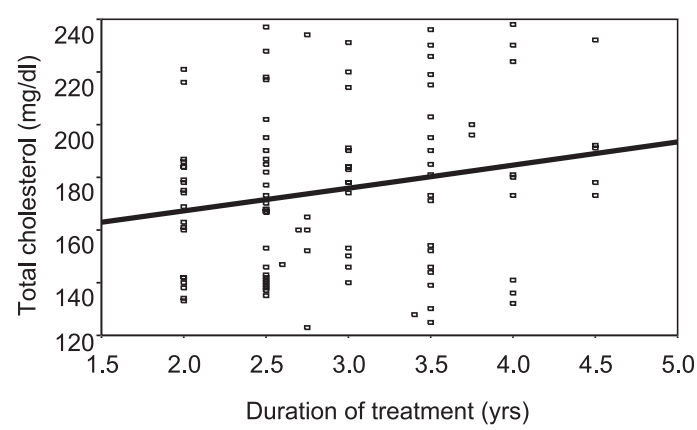

Fig.-1: Correlation between duration of treatment and total cholesterol $(n=107)$

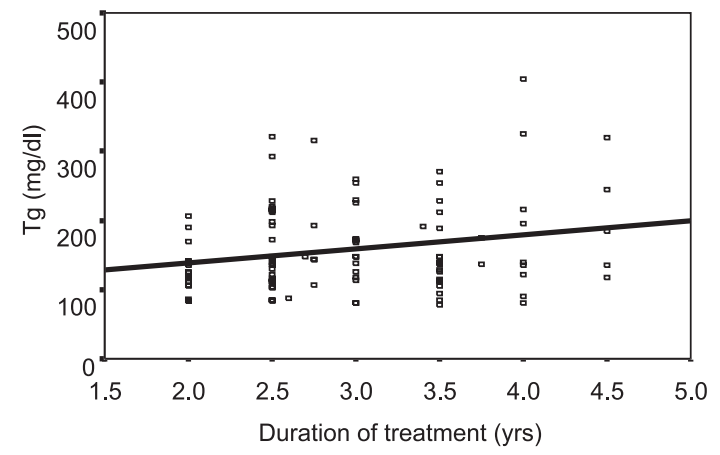

Fig.-2: Correlation between duration of treatment and triglycerides $(n=107)$ 


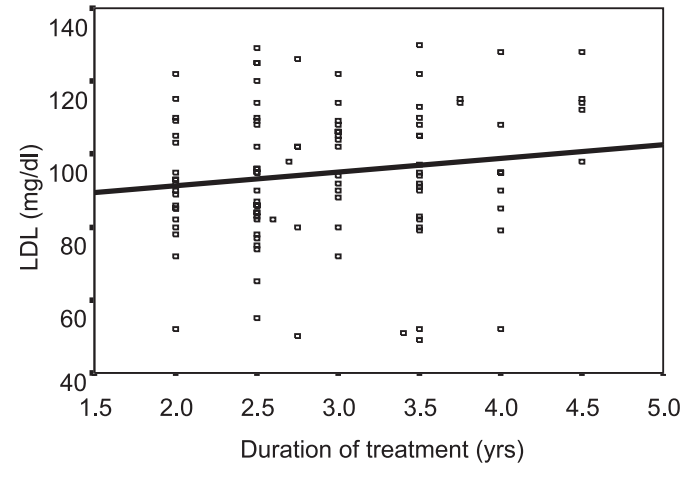

Fig.-3: Correlation between duration of treatment and LDL cholesterol $(n=107)$

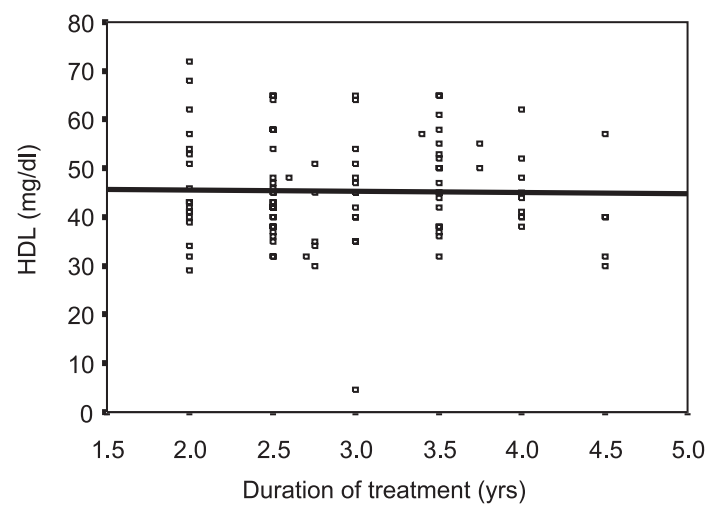

Fig.-4: Correlation between duration of treatment and HDL cholesterol $(n=107)$

Table IV

Comparison of dyslipidemia between sexes among case group

\begin{tabular}{lccc}
\hline Dyslipidemia & \multicolumn{2}{c}{ Sex } & p-value \\
\cline { 2 - 3 } & Male $(\mathrm{n}=31)$ & Female $(\mathrm{n}=76)$ & 0.211 \\
\hline Present & $13(41.9)$ & $42(55.3)$ & \\
Absent & $18(58.1)$ & $34(44.7)$ & \\
Lipid profiles & & & \\
Total cholesterol $(\mathrm{mg} / \mathrm{dl})$ & $167.2 \pm 28.9$ & $178.6 \pm 30.9$ & \\
Triglyceride $(\mathrm{mg} / \mathrm{dl})$ & $154.4 \pm 71.2$ & $158.7 \pm 60.2$ & \\
LDL $(\mathrm{mg} / \mathrm{dl})$ & $111.8 \pm 15.8$ & $113.4 \pm 17.3$ & \\
HDL $(\mathrm{mg} / \mathrm{dl})$ & $42.0 \pm 11.0$ & $46.7 \pm 10.1$ & \\
\hline
\end{tabular}

Figures in the parentheses indicate corresponding percentage;

\# Data were analysed using Chi-square $\left(\dot{\div}^{2}\right)$ Test.

There is positive correlation between duration of carbamazepine treatment and lipid profile( Fig.1). Serum total cholesterol and triglycerides bear linear relationship with duration of treatment of carbamazepine $(r=0.201, p=0.038$ and $r=0.223$, $p=0.021$ respectively).

The association of dyslipidemia differs with sex in epileptic patients receiving carbamazepine for more than 2 years. The proportion of dyslipdemia was considerably higher in the female patients than their male counterparts, although the difference was not statistically significant $(55.3 \%$ vs. $41.9 \%, p<0.211)$.

The mean serum creatinine and serum TSH were somewhat higher in the case group than those in the control group $(0.8 \pm 0.1 \mathrm{vs} .0 .7 \pm 0.2 \mathrm{mg} / \mathrm{dl}, \mathrm{p}<$ 0.001 and $3.2 \pm 0.5$ vs. $3.1 \pm 0.5 \mathrm{mlU} / \mathrm{L}, p=0.318$ respectively). However, random blood sugar was almost similar and within normal range in both the groups $(5.3 \pm 0.4$ vs. $5.2 \pm 0.8 \mathrm{mmol} / \mathrm{L} ; \mathrm{p}=0.138)$. The purpose of the study was to evaluate the longterm effect of carbamazepine on serum lipids.

\section{Discussion:}

The present study was carried out in BSMMU to find the effect of long-term use of carbamazepine on serum lipids of adult epileptic patients. The study included a total of 214 subjects with equal number of cases ( $n$ $=107)$ and controls $(n=107)$. The controls were selected from the epileptic patients receiving 
antiepileptic drugs other than carbamazepine. The study found that long-term use of carbamazepine alters the serum lipid components in patients with epilepsy and lead to dyslipidemia. The study also explored whether dyslipidemia can be caused by other factors including diabetes, renal impairment and thyroid disorders and concluded that dyslipidemia in epileptic patients could primarily be considered as due to long-term use of carbamazepine. Carbamazepine is one of the most frequently used antiepileptic drugs. There are at least 20 antiepileptic drugs that are currently being used.

The study results revealed that less participants in between 18-25 years were somewhat higher in case group compared to that in control group. However, the mean age of case and control groups were almost identical $(23.3 \pm 6.8$ vs. $23.8 \pm 6.4$ years, $p$ $=0.972$ ). The proportions of male and female patients were similar in both the study groups.

In the study all the lipid components, except total cholesterol were significantly abnormal in the case group compared to their control counterpart (Total cholesterol- $20.6 \%$ vs $13.1 \%$, p- 0.144 , Triglyceride$35.5 \%$ vs $23.4 \%$, p- 0.049 , LDL- $15 \%$ vs $0.9 \%$, p$<0.001$, HDL- $43.9 \%$ vs $18.7 \%$, p- $<0.001$ ). The study findings are consistent with the results from a study carried out by Pankaj K et al. (2004) $)^{17}$.

In the present study the number of patients with elevated triglycerides and LDL were significantly higher in patients receiving carbamazepine than those in the control group ( $35.5 \%$ vs. $23.4 \%, p=$ 0.049 and $15 \%$ vs. $0.9 \%, p<0.001$ respectively). The number of patients of low HDL was also significantly higher in the former group than that in the latter group $(43.9 \%$ vs. $18.7 \%, p<0.001)$. Nikolas $\mathrm{T}$ et al. ${ }^{18}$ revealed that compared with controls, epileptic patients on carbamazepine showed significantly higher serum TC, HDL-c, and LDL-C and non-significantly higher TG values which are not consistent with findings of the present study . Eiris and collegues ${ }^{19}$ also reported higher mean total cholesterol, HDL cholesterol and LDL cholesterol in patients receiving carbamazepine for a mean duration of 5.8 years .

Linvingston S (1976) ${ }^{20}$ also reported an increase in triglycerides in 35 epileptics on long-term treatment with Carbamazepine, which is consistent with this study. An increase in tryglycerides and cholesterol was observed by Reynolds et al (1976) ${ }^{21}$ in epileptic patients with long-term treatment of anticonvulsant drugs. In this study, the findings are partially compatible with the findings of their study.

The risk of developing dyslipidemia in epileptic patients receiving carbamazepine for at least 2 years or more was observed to be nearly three-fold ( $95 \%$ of $\mathrm{Cl}=1.6-5.0)$ higher than that in the control group ( $p<0.001)$. Hamed SA and Nabeshima T also reported that prolonged use of antiepileptic drugs (AEDs) are associated with multiple risk factors that are critically implicated in pathobiology and dysfunction of the vessel wall ${ }^{22}$.

The duration of treatment with carbamazepine was found to bear a linear relationship with total cholesterol and triglycerides $(r=0.201, p=0.038$ and $r=0.223, p=0.021$ respectively). Verrotti A et $\mathrm{al}^{23}$ assessed the effect of long-term treatment of (at least 2.5 years) phenobarbital, carbamazepine and sodium valproate on serum lipids and lipoproteins in epileptic patients and found that patients treated with carbamazepine had high levels of total cholesterol, triglycerides, LDL after longterm treatment .

The proportion of dyslipidemia was considerably higher in female epileptics than that in male epileptics which bears consistency with findings from Sudhop et. al. (1999) ${ }^{24}$ who observed HDL and LDL differences to be more pronounced in women treated with carbamazepine than those in men when compared with their controls.

Therefore, the findings of the present study are consistent with the results from similar studies i.e., long-term use of carbamazepine alters the serum lipid components in patients with epilepsy and lead to dyslipidemia. As the epileptic patients participated in the study were younger with mean age being 23 years, there is less possibility that dyslipidemia was influenced by age.

\section{Conclusion:}

A conclusion can be made from the above mentioned result that long-term use of carbamazepine in epileptic patients may cause dyslipidemia and the 
risk of having dyslipidemia in such patients is 3 times greater than the normal healthy population.

\section{References:}

1. Commission on Epidemiology and Prognosis, International League Against Epilepsy, 'Guidelines for epidemiologic studies on epilepsy Commission on Epidemiology and Prognosis, International League Against Epilepsy". Epilepsia 1993: 34; 592-96.

2. Blume W, Lüders H, Mizrahi E, Tassinari C, van Emde Boas W \& Engel J. 'Glossary of descriptive terminology for ictal semiology: report of the ILAE task force on classification and terminology', Epilepsia 2001; 42 (9); 1212-18.

3. Fisher R, van Emde Boas W, Blume W, Elger C, Genton P, 'Epileptic seizures and epilepsy: definitions proposed by the International League Against Epilepsy (ILAE) and the International Bureau for Epilepsy (IBE)', Epilepsia 2005;46 (4): 470-72.

4. Epilepsy: aetiogy, epidemiology and prognosis. World Health Organization. February 2001.Archived from the original on 2007-0518. http://web.archive.org/web/2007 0518073641/http://www.who.int/mediacentre/ factsheets/fs165/en/. Retrieved 2007-06-14.

5. The National Society for Epilepsy, 2009, what is Epilepsy? Available at: http:// www.epilepsynse.org.uk/AboutEpilepsy/ Whatisepilepsy.

6. Cascino GD. 'Epilepsy: contemporary perspectives on evaluation and treatment', Mayo Clinic Proc 1994;69:1199-1211.

7. Engel J Jr. 'Surgery for seizures', N Engl J Med 1996;334(10): 647-52.

8. Baker GA, Camfield C, Camfield P, Cramer JA, Elger CE, Johson LA et al. 'Commission on Outcome Measurement in Epilepsy-199497: Final Report', Epilepsia 1998; 39( 2): 213-31.

9. Engel J, 2001, 'A Proposed Diagnostic Scheme for People with Epileptic Seizures
And With Epilepsy: Report Of The llae Task Force On Classification And Terminology', Epilepsia 2001;42( 6):796-803.

10. Olson D 2008, 'Differentiating Epileptic Seizures From Nonepileptic Spells', Available at: http://www.consultantlive.com/consultantfor-pediatricians/article/1145470/1404577

11. The National Society for Epilepsy, 2009, what is Epilepsy? Available at: http:// www.epilepsynse.org.uk/AboutEpilepsy/ Whatisepilepsy.

12. Eiris JM, Lojo S \& Del Rio MC.Effects of longterm treatment with antiepileptic drugs on serum lipid levels in children with epilepsy'. Neurology 1995; 45:1155-57.

13. Tekgul H, Demir N,Gokben S. 'Serum lipid profile in children receiving anti-epileptic drug monotherapy: is it atherogenic'. J Pediatr Endocrinol Metab 2006; 19( 9): 1151-55.

14. Mantel-Teeuwisse AK, Kloosterman JME ,Maitland-van der Zee AH, 'Drug-induced lipid changes: a review of the unintended effects of some commonly used drugs on serum lipid levels'. Drug Saf 2001; 24:443-56

15. Zeitlhofer J, Doppelbauer A, Tribl G.'Changes of serum lipid patterns during long-term anticonvulsive treatment'. Clin Invest 1993;71: 574-78.

16. Demircioðlu S, Soylu A \& Dirik E. 'Carbamazepine and valproic acid: effects on the serum lipids and liver functions in children', Pediatr Neurol 2000; 23(2)142-46.

17. Pankaj K, Manoj T, Yogesh K, Tyagi AK, Ajay K, Yogesh KR. 'Effect Of Anticonvulsant Drugs On Lipid Profile In Epileptic Patients', Journal of Neurology 2004;3(1): 2-4.

18. Nikolaos $\mathrm{T}$, Stylianos $\mathrm{G}$, Chryssoula N, Irini $\mathrm{P}$, Christos $M$,Dimitrios T, 'The effect of longterm antiepileptic treatment on serum cholesterol (TC, HDL, LDL) and triglyceride levels in adult epileptic patients on monotherapy'. Med Sci Monit.2004; 10(4):50-52. 
19. Eiris JM, Lojo S, Del Rio MC , 'Effects of longterm treatment with antiepileptic drugs on serum lipid levels in children with epilepsy'.Neurology, 1995; 45:1155-7.

20. Livingston S, 'Pheytoin and serum cholesterol'. Br Med J 1976;1:586-88.

21. Reynolds EH, Chadwick D, Galbraith AW . 'One drug (Pheytoin) in the treatment of epilepsy' Lancet,1976;1:923-26.

22. Hamed SA and Toshitaka N. 'The High Atherosclerotic Risk among Epileptic: the
Atheroprotective Role of Multivitamins.' Journal J Pharmacol Sci 2005; 98(4): 340-53.

23. Verrotti A, Domizio S, Angelozzi B, Sabatino G, Morgese Giarelli F. 'Changes in serum lipids and lipoproteins in epileptic children treated with anticonvulsants'. J Paediatr Child Health 1997; 33(3): 242-45.

24. Sudhop T, Bauer J, Elger CE, Von Bergmann $\mathrm{K}$.'Increased high-density lipoprotein cholesterol in patients with epilepsy treated with carbamazepine: a gender-related study', Epilepsia 1999; 40:480-84. 